\title{
Time Series Forecasting of Price Volatility of Bivoltine Cocoons: An Application of GARCH Process and Artificial Neural Network
}

\author{
G.R. Halagundegowda*, B.M. Kantharaju and P. Kumaresan
}

Central Silk Board, Ministry of Textiles, Govt. of India, Karnataka, India

*Corresponding author

\section{A B S T R A C T}

\section{Keywords}

AIC, ANN, AR, BIC, Bivoltine Mulberry Cocoons, GARCH

Article Info

Accepted:

07 October 2019

Available Online:

10 November 2019
Accurate forecasting of prices of bivoltine mulberry cocoons is essential for planning and policy purposes. A study had been taken up to develop an appropriate model for forecasting the daily prices of biovoltine reeling mulberry cocoons by using the data collected for the period from $1^{\text {st }}$ April 2010 to $31^{\text {st }}$ of August 2019 from Government Cocoon Market (GCM), Ramanagaram, Karnataka. Generalized Auto Regressive Conditional Heteroscedastic (GARCH) and Artificial Neural Network (ANN) models were used to analyze the past behavior of time series data in order to make inferences about its future behavior for prices of bivoltine cocoons. A suitable model of GARCH process was identified based on the results of Akakie Information Criterion (AIC) and Bayesian Information Criterion (BIC).GARCH $(3,2)$ model exhibited lesser AIC and Schwarz criterion compared to other process. The estimates of $\operatorname{GARCH}(3,2)$ model showed that the coefficients of mean and variance equation were statistically significant at both $1 \%$ and $5 \%$ level of significance. A multilayered perceptron neural network was fitted, which had an input layer with 15 input nodes, Single hidden layer with 10 hidden node and an output layer with one output node. The forecasting performance was assessed for both the models by using Mean Square Error (MSE), Root Mean Square Error (RMSE) and Mean Absolute Percentage Error (MAPE) and found that the fitted $\operatorname{GARCH}(3,2)$ model was found to be better than ANN model.

\section{Introduction}

Sericulture is an agro based cottage industry, which plays an eminent role in the rural economy of India. India is the second largest producer of raw silk in the world with the annual production of 35,468 MT during 201819 and among the four different types of silk, mulberry silk is predominant and accounts for $71.46 \%$ of the total natural silk produced in
India. About 25,344 MT of mulberry raw silk was produced during 2018-19, in which the cross breed (multivoltine) silk production amounted to $18,357 \mathrm{MT}$ and the rest was bivoltine silk with 6987 MT. Karnataka is the largest silk producer in the country with the annual production of 9,525 MT of cross breed silk and 2,067 MT of bivoltine silk totaling to 11,592 MT of mulberry silk in 2018-19. India is traditionally a multivoltine silk producer. As 
bivoltine silk is qualitatively better than multivoltine silk, thrust is given by the Government to promote bivoltine silk production in the country. The bivoltine silk production has been growing remarkably well in the last few years.

However, as the bivoltine silkworm rearing is less hardy and more susceptible to diseases and fluctuations in temperature and humidity compared to cross breed silkworms, the production risk associated with bivoltine cocoon production by the farmers is more compared to cross breed cocoon production.

Price volatility affects both producers and consumers, for producers, price volatility increases production and investment risks, especially when the production cycle is long. For consumers, volatile prices make it difficult to make consumption decisions, especially when their income or budget is limited. Volatile prices can also reduce the accuracy of producers and consumers price forecasts and thereby causing welfare losses. Price volatilities may have negative impacts on economic growth and poverty, which are most damaging to economy of poor countries. Furthermore, higher and more unpredictable volatility may lead to an economic crisis.

Modeling price volatility helps to understand causes, patterns, and impacts, making it possible to mitigate the aforementioned risks and negative effects. Fitting an appropriate price discrete time volatility model can help producers and traders make proper production and investments decisions under conditions of price uncertainty. Producers need to know whether specific product prices are likely to decline in the future, while traders want to know the expected price volatility along the life of a contract. Governments as well as policy makers need better fitting models to manage the economy in volatile times, especially when the economy is affected by financial crisis or major depression. Such models also help them understand how markets behave during crashes.

As the prices of cocoon keep on changing from time to time, it creates risks to producers, reelers, twisters, processors, weavers and other parties involved different activities across the value chain. Thus, it is important to develop a reliable model to forecast the cocoon prices more accurately. In this context, this paper applies the most popular and widely used price volatility forecasting models namely $\mathrm{ARCH}$ and other GARCH mixtures and machine learning models like ANN for forecasting of price volatility of bivoltine cocoons.

\section{Materials and Methods}

Modeling of price volatility is central concept to understanding about price fluctuations. It is also necessary to develop powerful methods of forecasting future price trends. The daily price data of biovoltine reeling mulberry cocoons were collected for the period from $1^{\text {st }}$ April 2010 to $31^{\text {st }}$ of August 2019 for Ramanagaram cocoon market of Karnataka. The data was divided into two sets viz Training and Testing. $80 \%$ (2754 observations) were used for training and20 \% (693 observations) for testing the forecasting performance of model. The statistical software's namely R (v.3.3), Eviews- 8 and SPSS (Expert Modeler) were used for modeling and forecasting.

\section{GARCH model}

Generalized Auto Regressive Conditional Heteroscedastic (GARCH) model is an important time series model; as it enables modeling of volatility clustering. Volatility clustering occurs because periods of high volatility in time series are interspersed with periods of low volatility. Bollerslev (1986) extended the Engle's (1982) original work by 
developing a technique that allows the conditional variance to be dependent on previous own lags like an ARMA process. It involve two equations like mean equation and Variance equation as follows.

\section{Mean equation}

Auto regressive AR (p) series are used in mean equation model. The mean equation of a series (AR (p)), specified by using Partial Autocorrelation Functions (PACF), Autocorrelation Functions (ACF), Akakie Information Criterion (AIC) and Bayesian Information Criterion (BIC). This equation is important because if this is not correctly specified, the variance estimate will not be good either.

AR (1) process

$Y_{t}=\theta_{0}+\theta_{1} Y_{t-1}+\varepsilon_{t}$

$\varepsilon_{t}=\sigma_{t} \epsilon^{2}$

Here we assume that $\epsilon_{\mathrm{t}} \sim \mathrm{N}(0,1)$ and $\varepsilon_{\mathrm{t}} / \varphi_{\mathrm{t}-1} \sim \mathrm{N}$ $\left(0, \sigma^{2}\right)$

Where

$\varphi_{\mathrm{t}-1}$ is available information up to t-1 period

$\varepsilon_{\mathrm{t}}$ is disturbance term

$\sigma_{\mathrm{t}}$ is unconditionally standard normal variable

\section{Variance equation}

In case of variance equation, conditional variance is a linear function of square of error term and also a linear function of its own lags. The GARCH $(1,1)$ process is the most popular specification model in case of GARCH. It is in the form as below:

$\sigma^{2}{ }_{t}=\alpha_{0}+\alpha_{1} \varepsilon^{2}{ }_{t-1}+\beta_{1} \sigma^{2}{ }_{t-1}$
The generalization of this model is GARCH $(\mathrm{p}, \mathrm{q})$ process

$\sigma^{2}{ }_{t}=\alpha_{0}+\sum_{i=1}^{q} \alpha_{i} \varepsilon^{2}{ }_{t-1}+\sum_{j=1}^{p} \beta_{j} \sigma^{2}{ }_{t-1}$

A sufficient condition for the conditional variance to be positive is

$\alpha_{0}>0, \alpha_{i} \geq 0 \mathrm{i}=1,2 \ldots . \mathrm{q} ; \beta_{j} \geq 0 j=1,2 \ldots \ldots p ;$

This generalized ARCH (p, q) model called $\operatorname{GARCH}(p, q)$ allows for both autoregressive and moving average components in the heteroscedastic variance. If we set $\mathrm{p}=0$ and $q=1$, it is clear that the first order ARCH (1) model is simply a $\operatorname{GARCH}(0,1)$ model. If all $\gamma_{j}$ equal zero, the $\operatorname{GARCH}(\mathrm{p}, \mathrm{q})$ model is equivalent to an ARCH (q) model. In case of $\mathrm{ARCH}$ and GARCH models, maximum likelihood functions estimation (Fan and Yao, 2003) are commonly used. The most popular statistics used are Root Mean Squared Error (RMSE), Mean Absolute Error (MAE) and Mean Absolute Percentage Error (MAPE)

\section{Artificial Neural Network (ANN)}

Artificial neural networks can be defined as information processing tools, which mimic or copy the learning methodology of the biological neural networks. It derives its origin from human nervous system, which consists of massively parallel large interconnection of large number of neurons that activate different perceptual and recognition task in small amount of time.

ANNs imitate the learning process of the human brain and can process problems involving non-linear and complex data even if the data are imprecise and noisy. Thus they are ideally suited for the modeling of agricultural data which are known to be complex and often non-linear. A very 
important feature of these networks is their adaptive nature, where "learning by example" replaces "programming" in solving problems. This feature makes such computational models very appealing in application domains where one has little or incomplete understanding of the problem to be solved but where training data is readily available.

\section{Basics of artificial neural networks}

A neuron is a real function of the input vector $\left(\mathrm{y}_{1}, \ldots ., \mathrm{y}_{\mathrm{k}}\right)$. The output is obtained as $\mathrm{f}\left(\mathrm{x}_{\mathrm{j}}\right)=\mathrm{f}$ $\left(\alpha_{j}+\sum_{i=1}^{k} w_{i j} y_{j}\right)$, where $\mathrm{f}$ is a function, typically the sigmoid (logistic or tangent hyperbolic) function. A graphical presentation of neuron is given in Figure 1. Mathematically a multi-layer perception network is a function consisting of compositions of weighted sums of the functions corresponding to the neurons.

\section{Results and Discussion}

\section{GARCH model}

An AR-GARCH model was endeavored using the Eviews- 8 statistical package. The model was built by using daily price data of bivoltine cocoon from $1^{\text {st }}$ April 2010 to $10^{\text {th }}$ October 2017(Training Set: $80 \%$ of the sample)and the forecasting accuracy of the model tested by considering the remaining data on cocoon price from $11^{\text {th }}$ October 2017 to 31st August 2019 (Testing Set: 20\% of the sample)for forecasting out-of-sample set.

It can be observed from Figure 2 that the residuals of prices of bivoltine cocoon behaved high extent of fluctuations across the time period, which means irregular pattern of variation throughout the study period. This shows uncertainty of price called price volatility (periods of high swings in the price series followed with periods of low swings). In such situations, stochastic volatility models such as ARCH, GARCH etc., are normally used (Darekar et al., 2017). The price volatility of current study is plotted in Figure 3. The ARCH/GARCH effect was confirmed through Lagrange Multiplier (LM) test. The Table 1 depicts significance of Lagrange Multiplier (LM) test at 1 per cent level of significance. So, overall there is ARCH/GARCH effect for this series. The significance of the test indicates that the errors fluctuate across the sample and confirms the heteroscadasticity. Volatility predictive models are essentially constructed for the data suffers from heteroscadasticiy (Iqbal et al., 2010).

\section{Specifying a mean equation}

In this study, both AIC and Schwarz criteria were employed to select an appropriate mean model for the sample of the data available. Table 2 displays the summaries of the AIC and Schwarz criteria of different AR models. AR (3) model exhibited lesser AIC and Schwarz criterion. Therefore, AR (3) model was selected as the best model among several AR models.

\section{Specifying a volatility model}

Again, both AIC and Schwarz criteria were employed to select an appropriate GARCH model for the sample of the data available. The summaries of the AIC and Schwarz criteria of different GARCH models are shown in Table 3. GARCH $(3,2)$ model exhibited lesser AIC and Schwarz criteria compared to other series of GARCH models. Hence, GARCH $(3,2)$ model was selected as the best model among various GARCH models (Hansen et al., 2012).

\section{Simultaneous estimation of the mean and volatility equations}

The parameters of mean equation and variance equation of the prices of bivoltine cocoon 
were simultaneously estimated by considering GARCH models for conditional variance. The estimated parameters of both the mean and volatility equations are shown in Table 4 . The estimates of GARCH $(3,2)$ model show that the coefficients of mean and variance equation are statistically significant at both $1 \%$ and $5 \%$ level of significance. Further, $\alpha_{1}$ and $\beta_{1}$ are greater than zero. So this model is satisfying sufficient condition for the conditional variance as per the assumptions of the model (Guillermo 2018).

$\sigma^{2}{ }_{t}=3.803+0.963 \varepsilon^{2}{ }_{t-1}+0.967 \sigma_{t-2}^{2}+0.96$

Figure 4 explains the one-step ahead standard deviation for each observation in the sample.
Comparing this graph with that of the daily price, it is evident that the increase in the conditional standard deviation is associated with a clustering of large observations (Khalifa et al., 2011).

So, overall it can be concluded that the AR (3)-GRARCH $(3,2)$ model is the best among different GRARCH models for forecasting of the prices of bivoltine cocoon in Ramanagaram cocoon market. Yegnanew Alem Shiferaw (2012) reported similar results that GARCH $(1,1)$ models are the most 64ppropriate.06itted ${ }_{t}^{2}$ moddels2 $2 \sigma^{2}$ evaluate the volatility of the log-returns of prices of cereal crops.

Table.1 Heteroskedasticity Test for price of bivoltine cocoon

\section{Obs*R-squared 25.88936}

\section{Lagrange Multiplier (LM) test}

Prob. Chi-Square(1)

0.0000

Table.2 Autoregressive model selection for the prices of bivoltine cocoon using AIC and BIC

\begin{tabular}{|c|c|c|}
\hline & Akaike info criterion & Schwarz criterion \\
\hline $\mathbf{A R}(\mathbf{1})$ & 11.162 & 11.196 \\
\hline $\mathbf{A R}(\mathbf{2})$ & 10.032 & 10.208 \\
\hline $\mathbf{A R}(\mathbf{3})$ & 7.673 & 7.435 \\
\hline $\mathbf{A R}(\mathbf{4})$ & 8.187 & 8.264 \\
\hline $\mathbf{A R}(\mathbf{5})$ & 9.399 & 9.592 \\
\hline
\end{tabular}

Table.3 GARCH model selection for the prices of bivoltine cocoon using AIC and BIC

\begin{tabular}{|c|c|c|}
\hline Models & Akaike Info. Criterion & Schwarz criterion \\
\hline GARCH(1,0) & 12.56 & 12.65 \\
\hline GARCH(1,1) & 11.94 & 11.81 \\
\hline GARCH(1,2) & 11.65 & 11.32 \\
\hline GARCH(2,1) & 10.87 & 10.96 \\
\hline GARCH(2,2) & 8.32 & 8.25 \\
\hline GARCH(2,3) & 9.86 & 9.75 \\
\hline GARCH(3,1) & 8.16 & 8.13 \\
\hline GARCH(3,2) & 7.25 & 7.34 \\
\hline GARCH(3,3) & 10.69 & 10.72 \\
\hline
\end{tabular}


Table.4 Maximum Likelihood Estimates of $\operatorname{GARCH}(3,2)$ of prices of bivoltine cocoon

\begin{tabular}{|c|c|c|c|c|}
\hline Model Equations & Coefficient & Std. Error & Z-Statistics & Prob. \\
\hline \multicolumn{5}{|c|}{ Mean Equation } \\
\hline$\theta_{0}$ & 2.318 & 0.972 & 2.385 & 0.013 \\
\hline$\theta_{1}$ & 0.951 & 0.51 & 1.864 & 0.000 \\
\hline$\theta_{2}$ & -0.894 & 0.23 & -3.886 & 0.000 \\
\hline$\theta_{3}$ & 0.752 & 0.34 & 2.215 & 0.021 \\
\hline \multicolumn{5}{|c|}{ Variance Equation } \\
\hline$\alpha_{0}$ & 3.803 & 0.215 & 17.708 & 0.000 \\
\hline$\alpha_{1}$ & 0.963 & 0.050 & 19.384 & 0.000 \\
\hline$\alpha_{2}$ & 0.967 & 0.052 & 18.736 & 0.000 \\
\hline$\alpha_{3}$ & 0.964 & 0.060 & 15.945 & 0.000 \\
\hline$\beta_{1}$ & 1.004 & 0.073 & 13.736 & 0.000 \\
\hline$\beta_{2}$ & 1.022 & 0.019 & 54.154 & 0.000 \\
\hline R-squared & \multicolumn{4}{|c|}{0.89} \\
\hline Akaike info criterion & \multicolumn{4}{|c|}{7.25} \\
\hline Schwarz criterion & \multicolumn{4}{|c|}{7.34} \\
\hline Durbin-Watson stat & \multicolumn{4}{|c|}{1.67} \\
\hline
\end{tabular}

Table.5 Network Information for prices of bivoltine cocoon

\begin{tabular}{|c|c|c|}
\hline Input layer & $\begin{array}{c}\text { Covariates } \\
\text { No. of units } \\
\text { Rescaling methods of covariates }\end{array}$ & $\begin{array}{c}\text { Lag1,lag2,lag3...Lag15 } \\
\mathbf{1 5} \\
\text { Standardized }\end{array}$ \\
\hline Hidden Layers & $\begin{array}{c}\text { No. of hidden layers } \\
\text { of units in hidden layers } \\
\text { Activation Function }\end{array}$ & 1 \\
\hline Output Layer & $\begin{array}{c}\text { Dependent variables } \\
\text { Number of units }\end{array}$ & Hyperbolic tangent \\
\hline & Rescaling methods for scale dependents \\
& Activation function \\
Error function & 1 \\
& & $\begin{array}{c}\text { Standardized } \\
\text { Identity } \\
\text { Sum of squares }\end{array}$ \\
\hline
\end{tabular}

Table.6 Comparison of forecasting accuracy of GARCH and ANN models

\begin{tabular}{|c|c|c|}
\hline Statistics & GARCH & ANN \\
\hline MSE & 69.254 & 80.496 \\
\hline RMSE & 7.238 & 9.621 \\
\hline MAPE & 5.682 & 6.758 \\
\hline
\end{tabular}


Table.7 Observed and predicted prices of bivoltine cocoon

\begin{tabular}{|c|c|c|c|}
\hline Month & $\begin{array}{c}\text { Observed price } \\
\text { (Rs/kg) }\end{array}$ & \multicolumn{2}{|c|}{ Predicted price (Rs/kg) } \\
\cline { 3 - 4 } & 393 & GARCH & ANN \\
\hline $\mathbf{1}^{\text {st }}$ Sep 2019 & 402 & 391 & 395 \\
\hline $\mathbf{2}^{\text {nd }}$ Sep 2019 & 392 & 400 & 404 \\
\hline $\mathbf{3}^{\text {rd }}$ Sep 2019 & 393 & 390 & 396 \\
\hline $\mathbf{4}^{\text {th }}$ Sep 2019 & 391 & 395 & 395 \\
\hline $\mathbf{5}^{\text {th }}$ Sep 2019 & 394 & 390 \\
\hline $\mathbf{6}^{\text {th }}$ Sep 2019 & 415 & 413 & 418 \\
\hline $7^{\text {th }}$ Sep 2019 & 407 & 406 & 409 \\
\hline $\mathbf{8}^{\text {th }}$ Sep 2019 & 406 & 403 & 408 \\
\hline $\mathbf{9}^{\text {th }}$ Sep 2019 & 405 & 405 & 409 \\
\hline $\mathbf{1 0}^{\text {th }}$ Sep 2019 & 390 & 389 & 392 \\
\hline $\mathbf{1 1}^{\text {th }}$ Sep 2019 & 390 & 389 & 393 \\
\hline $\mathbf{1 2}^{\text {th }}$ Sep 2019 & 389 & 388 & 392 \\
\hline $\mathbf{1 3}^{\text {th }}$ Sep 2019 & 391 & 390 & 395 \\
\hline $\mathbf{1 4}^{\text {th }}$ Sep 2019 & 410 & 409 & 415 \\
\hline $\mathbf{1 5}^{\text {th }}$ Sep 2019 & 420 & 418 & 422 \\
\hline
\end{tabular}

Fig.1 Single neuron

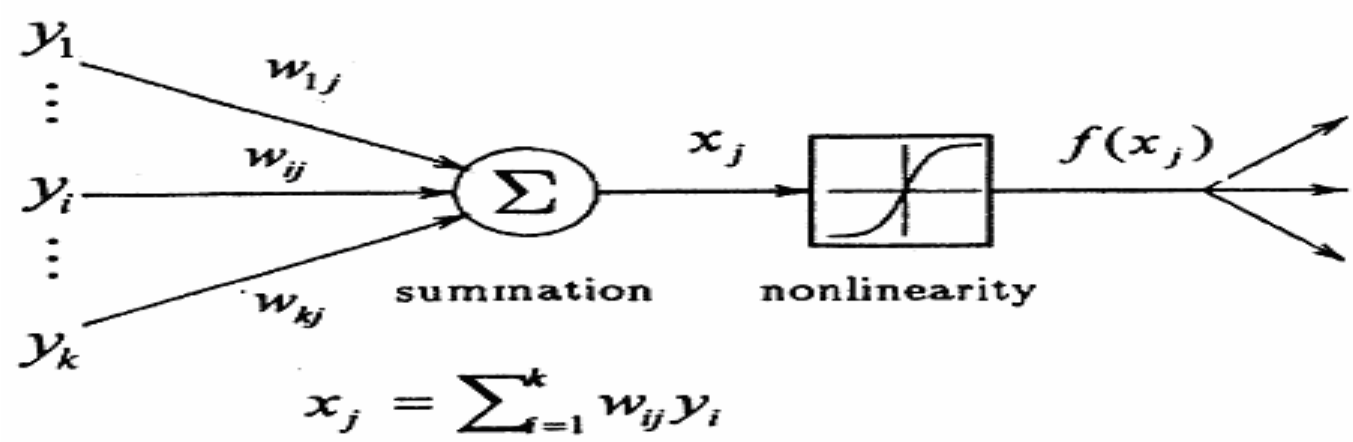

Fig.2 Residual plot of AR (3) process of prices of bivoltine cocoon

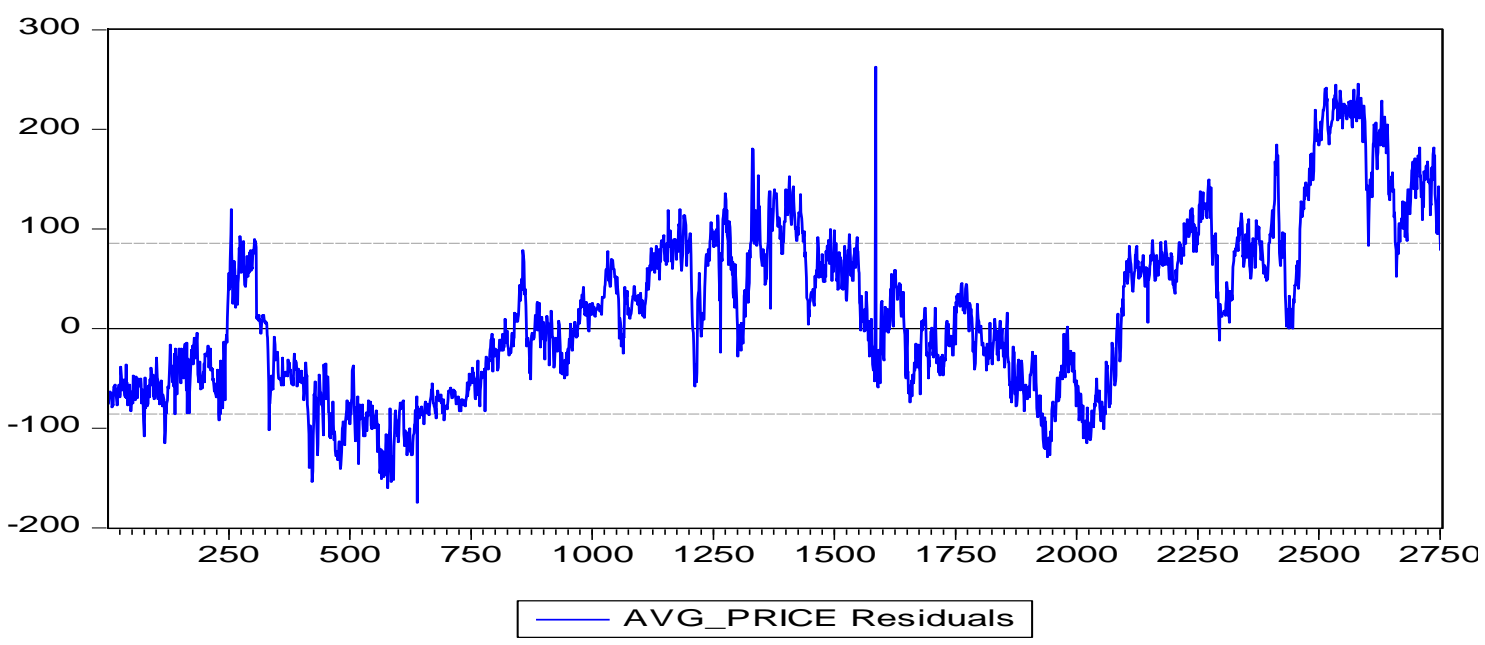


Fig.3 Volatility in prices of bivoltine cocoon

DAVGPRICE

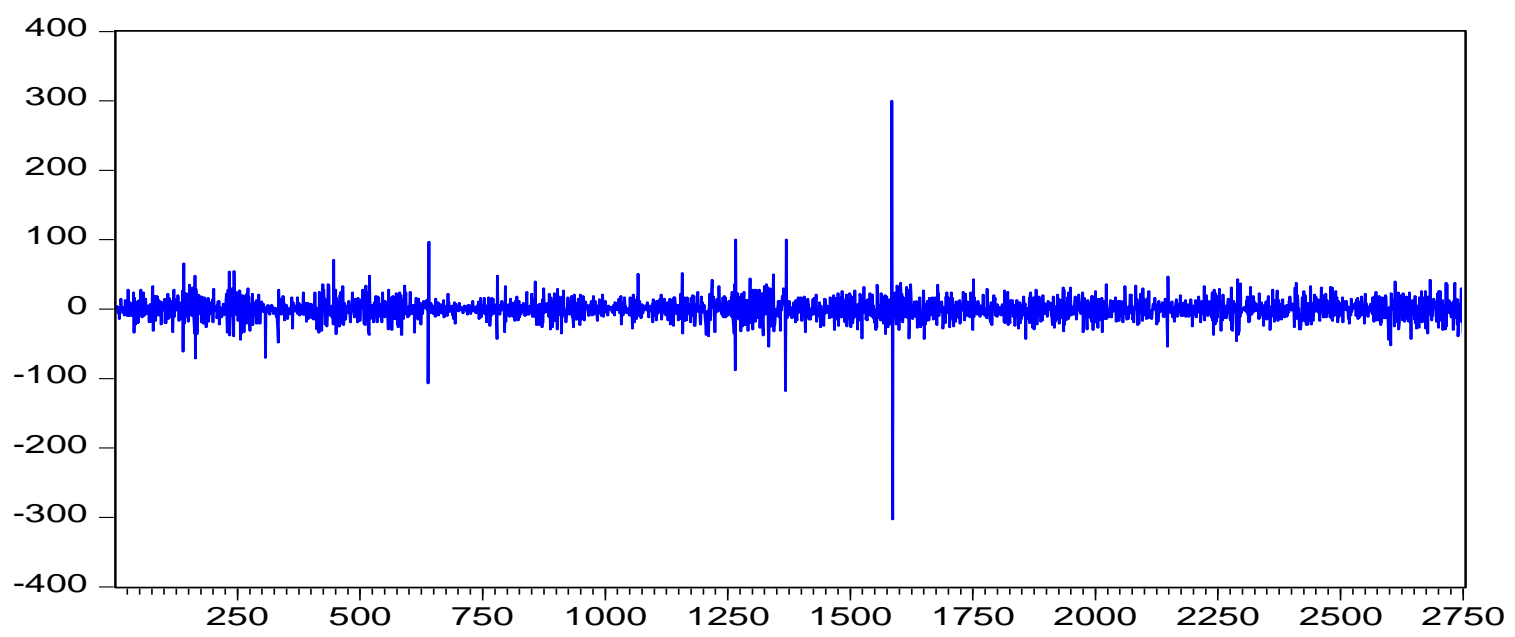

Fig.4 Estimated conditional standard deviation from $\operatorname{GARCH}(3,2)$ model

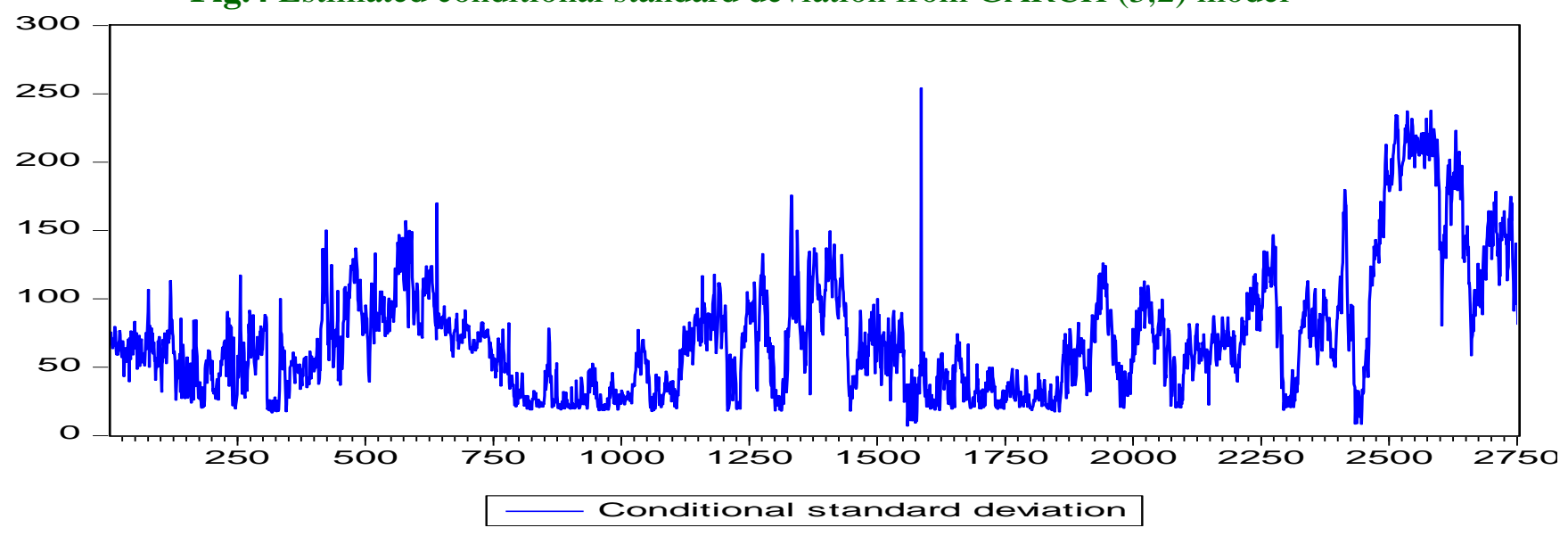

Fig.5 The architecture of the network fitted to time series of prices of bivoltine cocoon

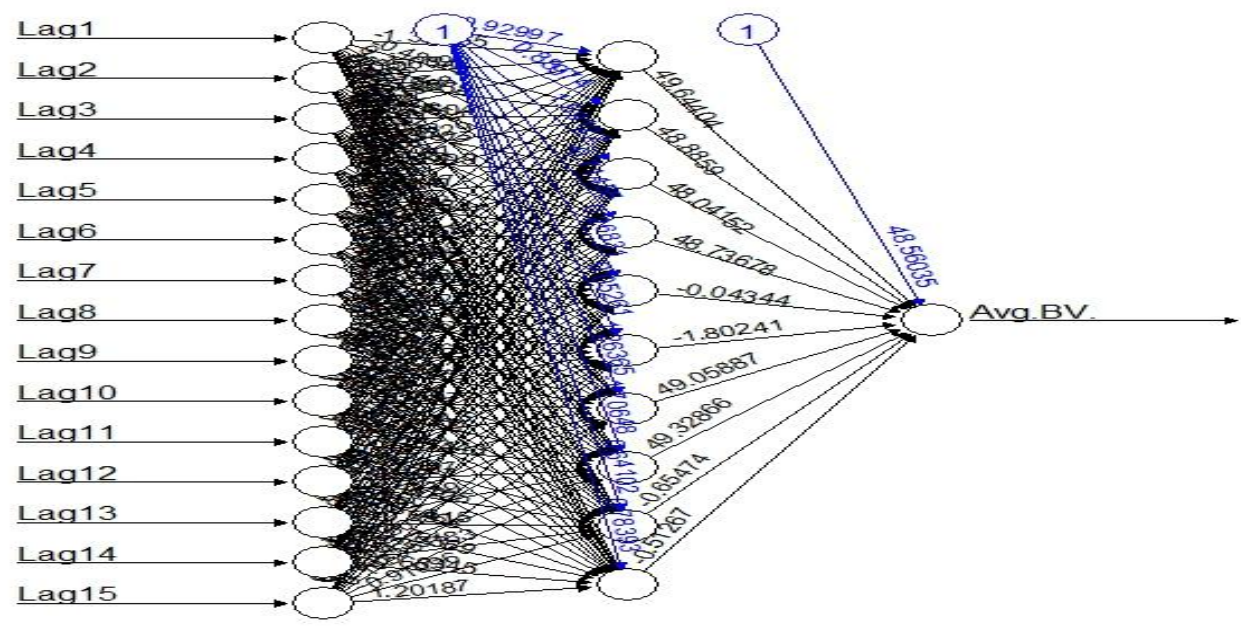


Fig.6 Trivariate plot of observed and predicted pricesfor GARCH and ANN models

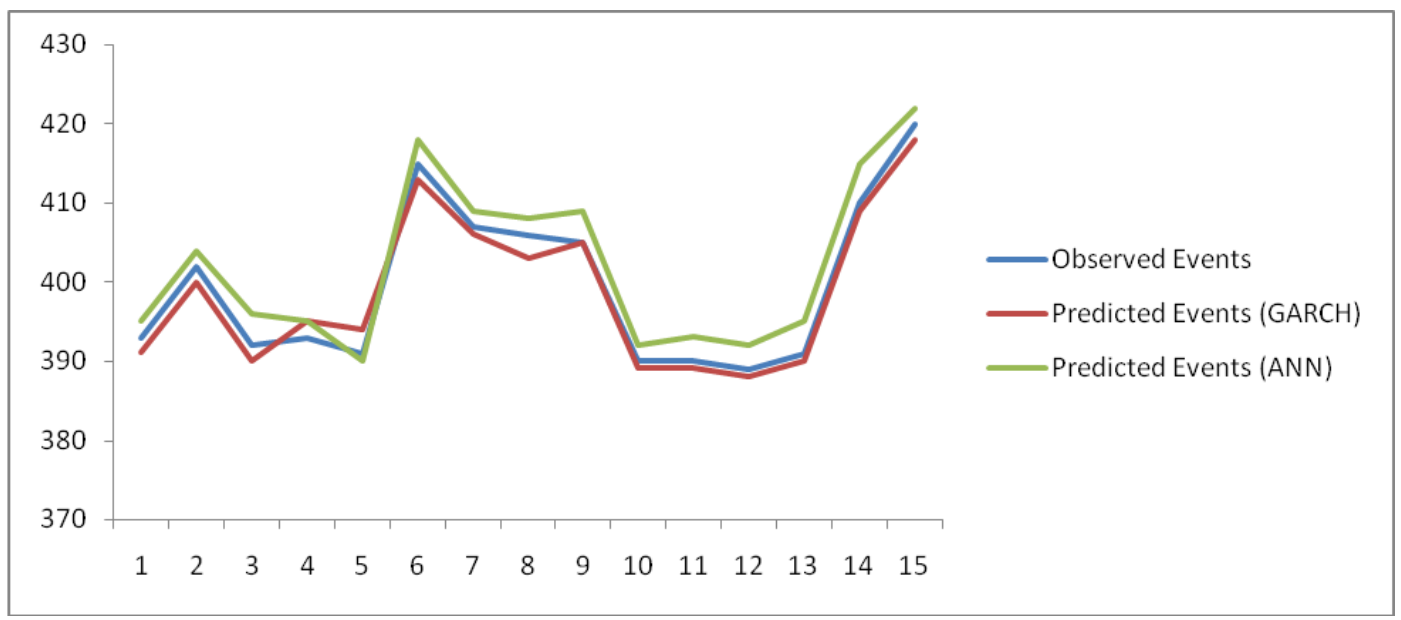

\section{Neural network model}

A feed forward neural network was fitted to the data with the help of $\mathrm{R}$ (v.3.3), where values of the time series by using 15 lags were taken as input vectors for forecasting. The data were divided into two sets viz., Training and Testing. As in the previous case, $80 \%$ (2754observations) were used for training and20\% (693 observations) for testing the forecasting performance of the model.

A multilayered perceptron neural network was fitted to the data. The number of hidden nodes varied from 1 to 200 . Thus, different numbers of neural network models were tried before arriving at the final structure of the model. Out of all neural network structures, a network model with 15 input nodes and 10 hidden nodes performed better than other competing models in respect of out-of sample prediction.

The information about the detailed neural network architecture is shown in Table 5. Here 15 input variables were used as covariates in analysis and the standardized rescaling method was used for adjusting the covariates. Scale dependent variables and covariates were rescaled by default to improve network training. All rescaling was performed based on the training data, even if a testing sample was defined. The network had an input layer with 15 input nodes (the number of units in the input layer was the number of covariates used in the model) One hidden layer with 10 hidden nodes and an output layer with 1 output node (Naveena et al., 2017).

In the hidden layer, there were numerous units and the activation function used was the hyperbolic tangent whereas in output vectors, identity function was used to provide the forecasted events. The architecture of the network was specified as 15-10-1 evolved from averaging of 25 iterated networks with 171 weights, which has been shown in the Figure 5.

Table 6 depicts the comparative study between volatility models (AR (3)-GARCH $(3,2)$ ) and machine learning model (ANN), which was carried out by using MSE, RMSE and MAPE statistic for assessing the forecasting accuracy of the models.

The MSE, RMSE and MAPE statistic are statistics computed by errors (Paul et al., 2009). It can be inferred from the table that MSE (69.254), RMSE (7.238) and MAPE (5.682) of AR (3)-GARCH $(3,2)$ model is less 
than MSE (80.496), RMSE (9.621) and MAPE (6.758) of ANN model. This clearly indicates an overall the superiority of AR (3)GARCH (3, 2) over ANN Model for forecasting of prices of bivoltine cocoon.

Table 7 provides the observed daily prices and predicted daily prices from both the models for the period of 15 days $\left(1^{\text {st }}\right.$ September 2019 to $15^{\text {th }}$ September 2019). The predicted price events followed random pattern across the order of sample price values (Yegnanew 2012).

The statistics like MSE, RMSE and MAPE statistics provide the numerical measures of accuracy of forecasting of any model, whereas biplot between observed and predicted events will provide the graphical way of assessing the prediction accuracy of any model. Figure 6 depicts the trend and patterns of observed and predicted price events for both the models. The predicted prices by GARCH model mimic more and adhere to the observed prices than that of ANN. This indicates the superiority of AR (3)-GARCH $(3,2)$ than in ANN Model for forecasting of prices of bivoltine cocoon (Karali et al., 2013).

This paper has compared the ANN and GARCH models in terms of both modeling and forecasting using daily price data of bivoltine cocoons. The GARCH model has provided a better forecast accuracy in terms of conventional MSE, RMSE and MAPE values as compared to the ANN model. The study has suggested an appropriate model for projection of bivoltine cocoon prices that can take into the consideration of adjustments of supply and demand in the future. The classical linear time series models are not always adequate for agriculture time series data, because that have both linear and non-linear structures. Therefore, it is better to try with volatility models and machine learning models which can be an effective way to improve forecasting performance. Based on the results obtained in this work, one can say that volatility models and ANN can increase forecasting accuracy. In further studies, one can improve the forecasting accuracy by using some other machine learning techniques such as Artificial Intelligence like Support Vector Machine, Decision Tree etc. This approach can be further evaluated by using other agricultural data real time data sets of different autoregressive and moving average orders so that practical validity of the model can be well known.

\section{References}

Bollerslev, T. 1986: Generalized Autoregressive Conditional Heteroscedasticity. Journal of Econometrics. 31: 307-327.

Darekar A and Reddy, A Amarender 2018: Forecasting Wheat Prices in India. Wheat and Barley Research 10(1).

Darekar, Ashwini. and Reddy, A Amarender2017: Price Forecasting of Pulses: Case of Pigeon Pea. Journal of Food Legumes 30(3): 42-46.

Engle, R. 1982: Autoregressive Conditional Heteroskedasticity with Estimates of United Kingdom Inflation. Econometrica. 50: 9871008.

Guillermo Benavides 2018: Price Volatility Forecasts for Agricultural Commodities: An Application of Volatility Models, Option Implied and Composite Approaches for Futures Prices of Corn and Wheat. Journal of Management, Finance and Economics, 3(2): 40-59.

Hansen, P. R. Huang, Z. and Shek, H. H., 2012: Realized GARCH: A Joint Model for Returns and Realized Measures of Volatility. Journal of Applied Econometrics, 27(6): 877-906.

Iqbal, F., Mukherjee, K., Baah, M., E. And Norte, N. N. E. 2010: M-Estimators of 
Some GARCH-type Models; Computation and Application: An Autoregressive Heteroscedastic (ARCH) Models, Statistics and Computing, 20: 435-445.

Karali, B., Power, G. J., 2013: Short-and Long-Run Determinants of Commodity Price Volatility. American Journal of Agricultural Economics 95 (3): 724-738.

Khalifa, A. Miao, H. and Ramchander, S., 2011: Return Distributions and Volatility Forecasting in Metal Futures Markets: Evidence from Gold, Silver, and Copper. The Journal of Futures Market, 31(1): 55-80.

Kobayashi, M. and Shi, X. 2005: Testing for EGARCH against Stochastic Volatility Models. Journal of Time Series Analysis, 26: 135-150.

Naveena, K. 2016: Statistical Modeling for Forecasting of Price and Export of Indian Coffee. Ph.D. Thesis, Banaras Hindu University, Varanasi, Uttar Pradesh, India.

Naveena K, Subedhar Singh and Abhishek Singh 2017:Time Series Statistical Modeling for Forecasting the Price of Indian Robusta Coffee, Trends in
Biosciences, ISSN 0974-8431, 41064112.

Paul, Prajneshu, RK, and Ghosh, H, 2009: GARCH Nonlinear Time Series Analysis for Modeling and forecasting of India's Volatile Spices Export Data, Journal of the Indian Society of Agricultural Statistics, 63(2):123-131.

Romero-Aguilar, R. S., 2015: Essays on the World Food Crisis: A Quantitative Economics Assessment of Policy Options. Doctoral Dissertation, The Ohio State University.

Serra, T., and Gil, J. M., 2013: Price Volatility in Food Markets: Can Stock Building Mitigate Price Fluctuations. European Review of Agricultural Economics 40 (3): 507-528.

Sundaramoorthy, C., Jha, G.K., Pal, S. and Mathur, V.C. 2014: Market integration and Volatility in Edible Oil Sector in India. Journal of the Indian Society of Agricultural Statistics, 68: 67-76.

Yegnanew AS, 2012: Modeling Volatility of Price of Some Selected Agricultural Products in Ethiopia: ARIMAGARCH Applications, Working papers series, Hawassa University.

\section{How to cite this article:}

Halagundegowda, G.R., B.M. Kantharaju and Kumaresan, P. 2019. Time Series Forecasting of Price Volatility of Bivoltine Cocoons: An Application of GARCH Process and Artificial Neural Network. Int.J.Curr.Microbiol.App.Sci. 8(11): 840-850.

doi: https://doi.org/10.20546/ijcmas.2019.811.099 